\title{
Os serviços nas sociedades contemporâneas e o serviço social: explicações e implicações ${ }^{a}$
}

\section{Services in contemporary societies and social service: explanations and implications}

\author{
Vera Maria Ribeiro Nogueira ${ }^{b}$
}

\begin{abstract}
Resumo
O presente texto enfoca algumas questões presentes no cotidiano do assistente social que tem sido objeto de reflexões pela categoria, como a legitimidade profissional, seu grau de autonomia e as suas particularidades na divisão social e técnica do trabalho. Enfocamse tais questões a partir da consideração do serviço social como um serviço, o que pode apontar algumas pistas para a elucidação das mesmas
\end{abstract}

Palavras-chave: serviços sociais, serviços, trabalho em serviços, política social, demandas sociais.

\begin{abstract}
Abstrac
The present text focuses on a number of questions present in the daily life of the social worker who has been the object of reflections by the category, such as professional legitimacy, its degree of autonomy and its particularities in the social and technical division of labor. These issues are focused on the consideration of social service as a service, which may point to some clues to elucidating them.
\end{abstract}

Keywords: social work, work in labor, social policy, social issues.

\section{Introdução}

A questão da identidade e autonomia profissional do assistente social e sua particularidade no vasto espectro da divisão sócio-técnica do trabalho é tema recorrente, tanto nas reflexões travadas ao nível acadêmico como no espaço interventivo. Neste sentido, o esforço para a identificação e afirmação do estatuto profissional tem passado por variáveis que incidem desde a sua legitimação pela via teórica, indo até a tentativa de reconhecimento pelo caminho eminentemente tecnicista, empírico e pragmático.

Observou-se, de forma recorrente, que os objetivos definidos para a ação profissional dificilmente ultrapassam os objetivos institucionais, não ocorrendo a incorporação
Kera Yvoty: reflexiones sobre la cuestión social. Vol. 1, 2016, 11-20.

ISSN (impreso): 2519-7797

a Este texto foi publicado anteriormente na Semina, editada pela Universidade Estadual de Londrina e republicado, com autorização da editora, com alterações significativas.

b Universidade Católica de Pelotas, Brasil.

Universidade Federal de

Santa Catarina, Brasil.

Conselho Nacional de

Desenvolvimento Científico

e Tecnológico. Ministério da

Ciência e Tecnologia, Brasil.

Correspondencia a:

veramrn@gmail.com

Cita:

Nogueira, V. M. R. (2016).

Os serviços nas sociedades contemporâneas e o

serviço social: explicações e implicações. Kera Yvoty: reflexiones sobre la cuestión social, 1, 11-20.

Recibido:

12 octubre 2016

Aceptado:

29 noviembre 2016 
da intencionalidade profissional na ação cotidiana, e essa submissão do fazer aos desígnios institucionais tende a obscurecer as possibilidades de se definirem objetivos e estratégias de ação que incidam sobre as reais necessidades dos usuários. Evidenciou-se, ainda, queaaçãoprofissional é paramentada por programas, projetos, normativas, instruções e manuais dos órgãos institucionais, geralmente deâmbito federal. Questão essa anunciada por Schütz e Mioto (2012, p. 97), segundo as quais, nesses casos, "[...] forja-se uma supremacia de técnicas e normas sobre o usuário". Assim, parece não ocorrer a reconstrução do objeto da ação a partir do aporte dos referenciais teórico-metodológicos críticos que subsidiam a prática do assistente social, tampouco realiza-se a leitura da realidade local, seja institucional ou relacionada à demanda. Isso resulta em três impasses adicionais para o campo profissional.

O primeiro, ao subordinarem as ações profissionais unicamente aos objetivos e às ações programáticas da instituição definidos em outras instâncias, esvai-se a direção social estratégica que o Serviço Social construiu, nas últimas décadas, tendo como norte a emancipação política, retornando-se a padrões tecnicistas e acríticos dominantes prévios ao movimento de reconceituação.

Osegundorefere-seà impossibilidade de "[..] transformarosobjetos deintervenção (presentes na capilaridade do movimento real) em objetos de conhecimentos, desde uma perspectiva ontológica e sóciohistórica [...]" (Mota, 2013, p. 6).

Por fim, o terceiro, não menos importante, diz respeito ao afastamento progressivo dos valores contidos no Código de Ética Profissional, entendidos eaprovado pela categoria como norteadores da ação, o que pode fazer com que o usuário não tenha suas demandas atendidas, ou serem atendidas de forma intermitente e incompleta, tornandose um número de um arquivo controlado pelas tecnologias de informação.

A resposta ao que foi observado encontra-se, no momento, ainda como uma questão em aberto, exigindo um esforço teórico para sua apreensão. Diante disso, este texto procura evidenciar as inter-relações entre alguns elementos condicionantes das ações profissionais que podem ampliar o debate desse assunto e indicar novos caminhos.

Nãodesconsiderando os condicionantes que incidem sobre as ações profissionais já sinalizados por Mioto e Lima (2009), outros elementos que imprimem direção e materialidadeàpráticapodemserincorporados a essas análises. Assim, parte-se do suposto de que a inserção do profissional, enquanto agente estatal, na implementação das políticas sociais, relacionada as nuances que o trabalho em serviço oferece na linha da autonomia do profissional executor dos programas sociais são elementos condicionantes que podem matizar a ação profissional, propiciando maior compreensão sobre os processos interventivos e, possivelmente, garantindo uma ação que vá além dos desideratos institucionais.

Parte-se da constatação de que não se pode perder de vista, nesta reflexão, os desafios derivados da rápida institucionalização das políticas sociais, bem como o desenho e as formas que assumiram os programas das grandes políticas sociais no Brasil, especialmente o Sistema Único de Saúde (SUS) e o Sistema Único de Assistência Social (SUAS). Ao situar-se o assistente social como um dos integrantes das equipes interprofissionais, tanto na saúde como na assistência, forçosamente essa inserção trouxe à tona questionamentos sobre as particularidades do fazer profissional do assistente social, a saber, as dificuldades de adequar-se às exigências do atual padrão gerencialista na área das políticas públicas e os entraves para encaminhar a ação em uma linha emancipatória, participativa e democrática.

Não se entende, todavia, ser esta uma reflexão ou argumentação acabada, pelo contrário, situa-se mais como um convite para novas abordagens, tendo como foco a qualificação profissional e a produção de conhecimentos em nossa área de 
competência e na área das Ciências Sociais. Busca-se tão somente dar continuidade, em parte, à linha argumentativa acerca da relação entre o Serviço Social e o trabalho em serviço, abordada por Karsch (1987), Nogueira (1990), Costa (1997), Britos (2006), Schütz (2009) e Schütz e Mioto (2012).

Ao se tomar a ação profissional como trabalho em serviço como um dos elementos para compreensão da relativa autonomia profissional, é preciso explicitar as razões e a perspectiva dessa abordagem. Não se pretende aqui repor as polêmicas quanto ao trabalho em serviço ser considerado produtivo ou improdutivo, material ou imaterial, produtor ou não de valor e sua contribuição na economia do desenvolvimento ${ }^{1}$, tampouco tenciona-se retomar um debate mais amplo sobre os serviços, seja no âmbito da teoria marxista, seja no âmbito da sociologia do trabalho ${ }^{2}$. São indicadas unicamente as características e propriedades dos serviços para sustentar a argumentação quanto à dificuldade de tratar as ações profissionais em uma perspectiva unicamente gerencial burocrática, despida de conteúdos políticos e de valores subjetivos. Indica, ainda, a dificuldade dos serviços, pela sua própria natureza, de serem controlados por agências centralizadas, o que confere um grau acentuado de liberdade de ação aos agentes implementadores de políticas públicas.

Nos debates sobre o tema a perspectiva encontrada apontam que a intervenção do assistente social localizase na implementação de políticas sociais públicas e privadas, isto é, refere-se às intervenções realizadas a partir dos desdobramentos da questão social.

Essa pauta de explicação reconhece que o serviço social se institucionaliza e

\footnotetext{
1 Sugerimos a produção acadêmica de autores que vêm, com extrema competência, analisando o valor do trabalho e sua relação com o trabalho em serviços, como Antunes (1999), Kon (2007), Meirelles (2008), Amorim (2009, 2012) e Rosso (2014).

2 Ver publicações de Nogueira (1990), Costa (1997), Britos (2006), Schütz (2009) e Schütz e Mioto (2012).
}

adquire a sua feição profissional a partir do atendimento de demandas típicas, postas pela modalidade de reprodução de uma dada sociedade. Em outros termos, a especificidade profissional se instaura e se cristaliza face ao atendimento de necessidades sociais historicamente construídas. Em sendo assim, cada configuração histórica exige formulações específicas face às demandas colocadas pelos atores sociais. Cumpre à categoria dos assistentes sociais responde-las, ou partilhar a resposta com outras categorias profissionais, que também buscam maior representatividade face ao todo social.

Conforme pontuado por Netto

[...] a afirmação e o desenvolvimento de um estatuto profissional (e dos papéis a ele vinculados) se opera mediantea intercorrência deum duplo dinamismo: de uma parte, aquele que é deflagrado pelas demandas que lhe são social mente colocadas, de outra, aquele que é viabilizado pelas suas próprias reservas de forças, aptas ou não para responder às requisições extrínsecas e este é, enfim, o campo em que incide o seu sistema de saber. (1990, p. 102)

Sinalizando a reflexão para o aspecto das requisições mencionadas, verifica-se que estas se enquadram como prestação de serviços sócio-assistenciais, viabilizados pela implementação e execução de medidas de política social. A tarefa posta ao serviço social postulada na esfera dos serviços possibilita algumas explicações e também determina implicações sobre "o que fazer" e o "como fazer" do assistente social, encaminhando algumas pistas para a questão de sua identidade, limite e autonomia.

Parametrando a reflexão, algumas considerações se fazem pertinentes:

- um ordenamento social, ao se desenvolver econômica e culturalmente, se complexifica e se organiza para atender as necessidades de seus componentes. Tais 
necessidades ultrapassam o plano biológico ese transformam em sociais, sendo historicamente conformadas de acordo com a expansão do complexo econômico dominante e as exigências de sua reprodução. A organização mencionada é institucional, e decorre da exigência de uma estruturação de poder para manter a estabilidade do todo social. Tal estruturação de poder não é aleatória, mas construída de maneira a garantir a hegemonia políticoideológica que mede a expansão do modo de produção dominante. É assim, a expansão do modo de produção social e sua requisição de continuidade que informam e conformam determinadas pautas de habituação e regulação, às quais acabam por institucionalizar-se como organizações específicas para oferecer às demandas as respostas exigidas, tanto no plano objetivo como simbólico;

- a medida que uma necessidade social e/ou econômica é respondida institucionalmente, isto é, organizada a resposta de uma forma específica e persistente, existe o que sé convencional chamar de serviço. $O$ atendimento das necessidades vitais foi, durante um longo período da história da humanidade, restrito a esfera privada - o comer, o reproduzir e o morrer eram manifestações pertencentes a vida familiar, ao âmbito doméstico. Com o desenvolvimento da cultura e a imposição de novos signos reguladores do sistema social, estas necessidades vitais são apropriadas pelo modo de produção capitalista e adquirem uma sobrefunção. A reprodução vai se expandindo para a esfera pública, ampliando os serviços para seu atendimento;

-os serviços, ao se organizarem, cumprem então uma dupla funcionalidade na ordem monopólica burguesa: atender as expectativas e demandas da sociedade e servir de controle às contradições sociais ela sociedade capitalista contemporânea. Assim, “[...] os próprios serviços sociais, que deveriam facilitar a vida social e a solidariedade social, têm efeito contrário" (Braverman, 1981, p. 48). Funções anteriormente cumpridas pela rede de solidariedade civil e famílias, passam a ser incorporadas ao Estado ou a organizações privadas, que tem seu aparecer como públicas. Na matriz funcional são consideradas como instâncias de manutenção da coesão social, servindo para garantir o equilíbrio do sistema em substituição a anteriores instâncias reguladora. A matriz marxista sinaliza que a expansão dos serviços é estrutural ao desenvolvimento do complexo produtivo.

A sociedade de classe no capitalismo monopolista cria uma civilização de serviços. As necessidades exacerbadas pela publicidade justificam novos serviços para novas necessidades que, no mundo moderno, desenvolvem uma proliferação de formas de atendimento, administrado por profissionais. (Karsch, 1987, p. 33)

- as instituições de serviço, características da etapa contemporânea do capitalismo monopólico, dão sustentação a esta forma de organização econômica na medida em que incorporam seus valores e os corporificam, veiculando-os para o conjunto social. As instituições de serviço são conformadas então por dois vetores: de um lado, as requisições da acumulação capitalistas e de outro a legitimação da ordem social, situando-se como o palco que 
concretiza a ação pública e privada.

\section{Os serviços - perspectiva conceitual}

As reflexões deste item fundamentam-se basicamente em Claus Offe (1989), e as inferências dele retiradas oferecem alguns caminhos para a discussão central, que são as implicações e algumas explicações relativas ao serviço social enquanto um serviço. Observa-se que os elementos conceituais aqui apresentados são sumários e servem tão somente para ilustrar as reflexões centrais.

A imprecisão e a generalidade das definições sobre o que significa trabalho em serviço são apontadas por Claus Offe, sinalizando que na literatura do setor terciário, este é usualmente uma categoria residual. É assim explicado mais pelos atributos negativos, pelo que deixa de ser, em relação a categoria trabalho.

O trabalho em serviços gera produtos não materiais, que não podem ser armazenados ou transportados. O trabalho em serviço não é, ou é menos, suscetível ã racionalização técnica e organizacional se comparado com o trabalho que produz bens. A produtividade do trabalho em serviços niro pdde ser medida e, por isso, seus padrões de produtividade não podem ser controlados. (Offe, 1989, p. 135)

No intento de superar tal imprecisão conceitual Offe e Berger têm procurado desenvolver um conceito de trabalho em serviços a partir de suas funções sociais.

Partem do princípio que tais atividades, incluindo as organizações e profissões, são tendencialmente voltadas para a manutenção das condições normais de urna sociedade. Os serviços estabelecem a articulação entre os elementos de todo social e contribuem para defender e preservar os elementos diferenciados da sociedade. A manutenção da norma, função dos serviços, tem dois aspectos que este deve dar conta: resguardar, de um lado, as partes do garantindo a individualidade, as variações e as contingências e situações diferenciadas que apresentam e, de outro, o resultado da intervenção deve preservar as regras, normas e valores gerais do todo.

Consequentemente, um critério de qualidade do trabalho em serviços é que ele não suprima a individualidade e a especificidade da situação de um "caso" em favor de uma norma de referência rígida nem inversamente, atribua uma tal às particularidades que as condições normais previstas por terceiros não sejam realizadas. (Offe, 1989, p. 136)

Ocorre assim uma polarização entre regras e normas gerais que devem seradotadas em cada "caso" específico a as normas a valores que devem ser respeitados. Com isso os meios específicos no sentido de se atingir um objetivo são referentes a especificidade de cada situação. As tarefas de mediação, sintetização e normalização, características dos serviços, são perpassadas sempre pela tensão existente entre os dois aspectos mencionados. "É preciso sempre normalizar simultaneamente o caso e individualizar a norma" (Offe, 1989, p. 137).

Da incumbência posta aos serviços, e da sua forma de concretização decorre uma situação, no mínimo problemática. Nas sociedades capitalistas contemporâneas os serviços são realizados sob a forma de trabalho, istoé, háa sua monetarizaçãoe, por conseguinte, o estabelecimento de relações contratuais entre os agentes envolvidos na ação. Tais relações contratuais, devido a mercantilização mencionada, tendem a exigir uma racionalidade que é própria do trabalho e muito difícil de ser obedecida no caso dos serviços. O serviço passa a ser medido e "cobrado" pelo mesmo parâmetro do trabalho, olvidando-se que o primeiro tem uma racionalidade diferente e não se enquadra na racionalidade do processo produtivo, da organização industrial. A racionalidade dos serviços subordina-se 
às sequencias da mediação e conciliação, atentando para os dois aspectos que lhes dão forma a normatização e a particularização. Implica em espaço de manobra que dê oportunidade de responder "aqui e agora" as ordens diferenciadas de exigências. Contém uma especificidade radicalmente oposta a racionalidade do trabalho, que define a relação direta entre meio e fim, diminuindo o espaço de manobra dos trabalhadores e sujeitando-os a um melhor controle externo. A área dos serviços, pela sua natureza mesma, guardando uma relativa autonomia do ator envolvido, uma vez que não há intermediação direta entre meio e fim, devendo os objetivos e encaminhamentos serem fixados de maneira não estandartizada, resguardando a tensão entre a normalização e a particularização. Assim o produto dos serviços e a sua quantificação e qualificação dificilmente são medidos em termos objetivos e concretos. Os resultados previstos da ação nos serviços serão positivos se houver um equilíbrio entre os processos de individualização/diferencial e o processo de coordenação padronização.

Somente um lado do processo de abarcado se, por exemplo, é estabelecido que o trabalho de um médico é curar paciente, ou que o trabalho de um vendedor é vender mercadorias. Embora isso possa estar certo, também é verdade, reciprocamente, que os padrões reconhecidos de "tratamento bem sucedido" ou de "venda" assim como os meios específicos para se atingir esses objetivos, devem ser concretamente determinados em relação à especificidade do caso. (Offe, 1989, p. 137)

Todos os tipos de trabalho em serviço, em sua função social de mediar e normalizar, apresentam ainda dois problemas interligados, como decorrência mesmo da função social e da forma de organização do trabalho em serviço, isto é, o processo de mercantilização/monetarização típico da sociedade terciária. Os serviços são adequados, se equilibram a tensão entre a particularidade e a norma, em uma relação que é relativamente indefinida e que deve ser decidida no plano individual, pelo responsável pelo serviço. Esse primeiro dilema, no dizer de Claus Offe, ocorre ao nível individual da ação, e deve ser resolvido pelo recurso a orientação normativas, à ética profissional, às qualificações sociais e ao arcabouço informativo das profissões. O segundo dilema aparece devido ao fato das atividades em serviços serem desempenhadas como trabalho contratual, em nível organizacional maior.

Quando isso de fato (como no caso da educação através de uma organização baseada no trabalho (work), e não através de famílias ou grupos de indivíduos de uma mesma categoria), os critérios de racionalidade da organização (eficiência, eficácia, controle, etc.) chocam-se com as necessidades de autonomia e flexibilidade enquadradas pelo primeiro dilema mencionado. (Offe, 1989, p. 139)

Supõe esse problema a diferença entre as sinalizações e orientações burocráticas e as profissionais, pano de fundo de reiteradas e polêmicas discussões entre objetivos profissionais e institucionais.

As concepções de Offe e Berger foram ampliadas e atualizadas por autores que se dedicam ao tema. Nessa linha uma concepção ampla é indicada por Rosso (2014, p. 76), que postula que “[...] atividades em serviços compreendem uma quantidade muito grande de ações que possibilitam a circulação e o consumo, além de um conjunto de outras atividades a ela agregadas e de natureza diversa”. Segundo esse autor as atividades desenvolvidas pelos servidores do âmbito estatal são classificadas como serviço desde que sejam prestadas aos cidadãos e que a relação entre o trabalhador e o empregador (Estado) extinga-se no pagamento do salário. 
Observa que o Estado presta serviços de educação, de saúde pública e outros que não dependem de relações econômicas diretamente, mas sim "[...] do patamar de civilidade ou barbárie de cada nação" (Rosso, 2014, p. 86); ou seja, os serviços na esfera da proteção social pública são instituídos, além de sua funcionalidade no campo econômico, visando ao atendimento das demandas sociais, viabilizado através de medidas de política social. O alcance, o desenho e a regulação das políticas sociais são igualmente construções sóciohistóricas, derivadas da apreensão do nível de igualdade ou desigualdade aceito em cada sociedade, indicados pela concepção de cidadania adotada e justificada. São, enfim, modeladas pelas relações estabelecidas entre a sociedade e o Estado.

Meirelles (2008) propõe uma abordagem conceitual sobre serviços partindo da hipótese de que a sua natureza específica reside em ser essencialmente realização de trabalho, ou seja, trabalho em processo, trabalho em ação. A mesma autora sintetizauma caracterizaçãodosserviçospor autores contemporâneos em duas grandes linhas: os serviços centrados na oferta e os serviços centrados na demanda, conforme afirma Meirelles (2008). Quando a análise é centrada na oferta, os autores indicam três características que diferem das demais atividades econômicas: fluxo, variedade e uso intensivo de recursos humanos. O fluxo está relacionado com as propriedades de simultaneidade e continuidade da prestação do serviço, que se mantêm contínuos no tempo e no espaço. A simultaneidade resulta em outras duas características dos serviços: a inestocabilidade, pois não se permite estocar o que foi produzido, e a incomensurabilidade, sendo os seus resultados de difícil aferição e, portanto, controle. A variedade reside na multiplicidade de técnicas de produção dos serviços e na variação em tamanho e margem de lucro quando realizado em empresas produtivas. O uso intensivo de recursos humanos é a terceira característica apresentada pelos serviços, sendo pela sua natureza relacional, intensamente interativa, dependente de inúmeros fatores, o que sinaliza para a impossibilidade de ser avaliado pelo tempo despendido em sua prestação (Meirelles, 2008). O trabalho em serviço supõe uma troca entre pessoas singulares em uma relação geralmente face a face. Entram nessa troca elementos subjetivos relativos aos valores, história de vida, cultura e expectativas diferenciadas. Portanto, um serviço prestado é sempre único, não podendo ser repetido igualmente em outras situações. Não é similar a um produto que pode ter seu tempo de fabricação aquilatado. Ao depender de ações interativas entre pessoas, sua trajetória quase sempre é processual, variável no tempo, dependendo da maior ou menor facilidade de trocas de informações e orientações, ou, em outros termos, poderá exigir várias atividades para se alcançar seu escopo final. Pela mesma razão, os serviços têm sua produção e consumo imediatos, não sendo possível seu armazenamento para uso futuro, ou, como anteriormente dito, possui a característica da inestocabilidade.

Os autores que centram a análise dos serviços a partir da demanda objetivam apreendê-los tendo em vista os fins a que se destinam e o seu consumidor - função e público-alvo. Classificam-nos, assim, em relação ao tipo de atividades: (a) serviços intermediários, que se referem às atividades produtivas industriais e empresariais; e (b) serviços finais ligados aos serviços de consumo tanto individuais (lazer, serviços domésticos) como coletivos (segurança, saúde, educação).

Essas duas visões dicotômicas têm sido superadas por alguns autores, e Meirelles (2008) sinaliza para novas alternativas decorrentes das mudanças técnicas e econômicas na área dos serviços, as quais mantêm as propriedades e as características das análises do lado da oferta e da demanda.

Outro elemento relevante aos objetivos dessetexto em relaçãoaos serviços, 
igualmente apontado por Meirelles (2008), éo uso intensivo da informação, a habilidade de processar e interpretar informações que devem ser aprendidas pelos consumidores dos serviços. Tendo em vista a dimensão sócio-educativa do Serviço Social, essa troca de informação é um dos elementos fortemente presentes na ação cotidiana, confirmando o trabalho profissional como um serviço.

Ainda que contenha características e propriedades que o particularizem, as atividades de serviço, ao serem monetarizadas pela sua realização, se configuram como trabalho, daí se adotar a terminologia trabalho em serviço, embora não possam ser analisados e avaliados pela mesma lógica. A intenção de tratar o trabalho em serviço, e a partir de suas particularidadeseespecificidadescomoestas incidem no fazer profissional e impactam a ação dos agentes implementadores do Estado, influenciando especialmente a autonomia que lhes é conferida pelo tipo de vínculo institucional estabelecido, não é uma abordagem inovadora. Em 1987, Ursula Karch publicou um livro sobre o tema, e posteriormente outros autores adensam a compreensão sobre a relação entre o Serviço Social e os serviços 3 .

\section{O serviço social na esfera dos serviços: implicações e explicações}

A compreensão da natureza, tarefas e funções dos serviços pareceampliar e orientar a explicação para algumas questões presentes no cotidiano do assistente social legitimidade, particularidade e autonomia relativa. A legitimidade articula-se estreitamente à particularidade profissional, isto é, uma profissão institucionaliza-se e se mantém, é validada diante do todo social à medida em que oferece respostas às solicitações especificas que lhes são postas por essa mesma sociedade.

No caso do serviço social, algumas

3 Ver publicações de Nogueira (1990), Costa (1997), Britos (2006), Schütz (2009) e Schütz e Mioto (2012). distorções têm marcado historicamente a identificação de sua legitimidade. Possivelmente devido a necessidade de superar uma identificação com o trabalho voluntário assistencial, houve a tentativa de firmar-se como ciência, dado que o "status" científico poderia transpor a subalternidade que pairava sobre a profissão, face a outras mais valorizadas, diferenciando-a ainda de ações benemerentes. "Na escala em que remeteu o seu perfil profissional a um suposto fundamento "científico" creditouse essencialmente a este as suas inflexões prático-profissionais" (Netto, 1990, p. 102). Houve a subsunção da perspectiva interventiva de atendimento às demandas histórico-sociais ao sistema de saber que orienta o atendimento a tais exigências. Reconhecer então, como base de afirmação do serviço social, as possibilidades reais de respostas às solicitações feitas à é relevante para sua dade.

Interligando a natureza interventiva do Serviço Social e sua configuração como um serviço, há o reconhecimento de seus limites e/ou relativa autonomia. Enquanto serviço, dentro da particularidade que lhe é própria, deve firmar-se pela via da ação técnica, incluindo o sistema de saber que orienta sua intervenção. Resgata-se aqui a relevância da teoria e procedimentos que são por ela informados, no sentido mesmo de resolver tensão entre a individualização e a normaliza-alinhavando direção política da ação. A competência teórica, técnica política devem estar interligadas, garantindo a efetividade e a eficiência da ação através do reconhecimento da dinâmica da sociedade e sua implicação para o serviço social do uso adequado desse arsenal teórico para intervir no âmbito específico dos desdobramentos da questão social. No dizer de Iamamoto:

Respondera esses quesitos (demandas imediatas feitas à profissão) supõe uma consistente formação Téoricometodológica, um acompanhamento pertinaz e perspicaz da dimimica histórico-conjuntural que permite ler em situações singulares, as particu 
laridades e as leis do movimento social, decifrando, em toda a sua complexidade, as manifestações cotidianas da vida social. Mas supõe, ainda, uma compet ncia, técnico-política que contribua para a formulação de respostas precisas ao que fazer, como e porque fazer. (1990, p. 12)

É a necessária competência teórica, técnica e política que deslinda e ilumina as situações de individualizaçãoe normalização que os serviços sociais devem dar conta de articular em sua tarefa de mediação de sintetização nas ações cotidianas.

Resgatar a racionalidade própria dos serviços - mediação e sintetização e articulá-la as com a prática profissional contribui para a superação de muitas angústias profissionais, que se vêm presos a racionalidade que é inerente ao trabalho, dada a mercantilização dos serviços. Contribui ainda para o reconheci mento da polarização entre a lógica institucional e profissional, identificada a natureza diferenciada que orientam suas ações.

Lembrar, entretanto, que, enquanto atividade profissional, tem uma subordinação institucional - trabalho em serviço localiza-se subordinada formalmente aos interesses do modo de organização social construída pelo modo de produção capitalista, e que tal subordinação não é somente do ponto de vista do assalariamento, mas também no plano ideológico. Não é tão determinada esta influência em razão da peculiaridade de constituir-se enquanto um serviço. Não contém o controle do tempo e cadência de movimentos como o operário da produção. O grau de autonomia é, pelos motivos anteriormente apontados, é muito maior no trabalho em serviços - autonomia técnica, política e teórico-metodológica.

Emtermosoperativos, essaautonomia vai estar presente nos atos cotidianos, que contém em si os elementos fundantes e determinantes da ação profissional - a forma de atendimento e as tarefas pol íticas que se insinuam nessa intervençã

\section{Algumas considerações}

Quando ao trabalho em serviços, se recuperou as particularidades dos serviços evidenciando sua lógica própria, com características que dificultam seu controle intensivo, ocorrendo assim um espaço de liberdade em que o profissional imprime seus valores, sua cultura e seu ideário profissional. Partiu-se do suposto que pensar na atuação dos assistentes sociais enquanto agente implementador no espaço estatal implicou reconhecer o Estado como instituição.

Para os assistentes sociais com vínculo de trabalho no Estado, resgatar a racionalidade própria dos serviços mediação e sintetização e articular com a prática profissional contribui para a superação de muitas angústias profissionais, que se vêm presos à racionalidade que é inerente ao trabalho, dada a mercantilização dos serviços. Contribui ainda para o reconhecimento e superação da polarização entre a lógica institucional e profissional.

As considerações aqui colocadas pretendem oferecer algumas pistas para a elucidação de questionamentos e dúvidas que permeiam a ação profissional do assistente social. $\mathrm{O}$ que se pretendeu foi iniciar um debate buscando elucidar o significado da prática em serviços, debate este que qual deverá ser ampliado com novas contribuições, reconhecendo ser um tema presente que deve ser qualificado no campo da construção teórica elucidando os aspectos concretos da ação profissional.

\section{Referências Bibliográficas}

Amorim, H. (2009). Trabalho imaterial: Marx e o debate contemporâneo. São Paulo: Annablune \& Fapesp.

Amorim, H. (2012). Trabalhoimaterial, classe social e qualificações profissionais. In J. S. Souza \& R. Araújo (Eds.), Trabalho, educação e sociabilidade (pp. 154-172). Maringá: Práxis \& Massoni.

Antunes, R. (1999). Os sentidos do trabalho: 
ensaio sobre a afirmação e a negação do trabalho. São Paulo: Ed. Boitempo.

Braverman, H. (1981). Trabalho e capital monopolista: a degradação do trabalho no século XX. Rio de Janeiro: Zahar.

Britos, N. (2006). Ambito profissional y mundo del trabajo: politicas sociales y trabajo social em los anos noventa. Buenos Aires: Espacio Editorial.

Costa, M. D. H. (1997). Os serviços na contemporaneidade: notas sobre $\mathrm{o}$ trabalho em serviço. In A. E. Mota (Ed.), A nova fábrica de consensos: ensaios sobre a reestruturação empresarial, o trabalho e as demandas ao serviço social (pp. 97-113). São Paulo: Cortez.

Iamamoto, M. (1990). O ensino da prática. $A$ proposta de trabalho para a disciplina: metodologia aplicada. Rio de Janeiro: UFRJ.

Karsch, U. M. (1987). O serviço social na era dos serviços. São Paulo: Cortez.

Kon, A. (2007). Sobre a economia política do desenvolvimento e a contribuição dos erviços. Rev. Econ. Polit., 27(1), 130-146. doi: 10.1590/So101-31572007000100007

Meirelles, D. S. (2006). O conceito de serviço. Rev. Econ. Polit., 26,(1), 119-136. Recuperado de http://www.scielo.br/ pdf/rep/v26n1/ao7v26n1.pdf

Mioto, R. C. T. \& Lima, T. S. (2009). A dimensão técnico-operativa do serviço social em foco: sistematização de um processo investigativo. Revista Textos $\mathcal{E}$ Contextos, 8(1), 22-48.

Mota, A. E. (1987). Em busca de uma nova legitimidade para o serviço social de empresa. Serviço Social e Sociedade,
(26), 156-164.

Mota, A. E. (2013). Serviço social brasileiro: profissão e área do conhecimento. Rev. Katálysis,16(ne),17-27.Recuperadodehttp:// www.scielo.br/scielo.php?script $=$ sci arttext\&pid=S1414-49802013000300003\&ln $\mathrm{g}=$ en\&nrm=iso

Netto, J. P. (1990). Autocracia burguesa e serviço social (Tese de Doutoramento). Pontifícia Universidade Católica, São Paulo.

Nogueira, V. M. R. (1990). Os serviços e o serviço social: explicações e implicações. Semina, 11(3), 160-164, set. 1990. Recuperado de http://www.uel. $\mathrm{br} / \mathrm{revistas} / \mathrm{uel} /$ index.php/seminasoc/ article/view/9251

Off, C. (1984). Problemas estruturais do estado capitalista. Rio de Janeiro: Tempo Brasileiro.

Off, C. (1989). Capitalismo desorganizado. São Paulo: Brasiliense.

Rosso, S. D. (2014). Teoria do valor e trabalho produtivo no setor de serviços. Cad. $\mathrm{CRH}$, 27(70), 75-89. Recuperado de http:// www.scielo.br/scielo.php?script $=$ sci arttext\&pid=So103-49792014000100006\&ln $\mathrm{g}=\mathrm{pt} \& \mathrm{nrm}=\mathrm{iso}$

Schütz, F. (2009). O debate sobre os serviços na política social: implicações para o Serviço Social (Dissertação de Mestrado). Universidade Federal de Santa Catarina, Santa Catarina.

Schütz, F. \& Mioto, R. T. (2012). O trabalho em serviços: contribuições para o debate do serviço social. Em Pauta, 10(2), 83101. 